\title{
Ciências Sociais e Saúde: uma análise in vivo
}

CANESQUI, Ana Maria.

Ciências Sociais e Saúde no Brasil.

São Paulo: Hucitec, 2007.

Coleção Saúde em Debate. Série Linha de Frente. 122p.

| ${ }^{1}$ Miguel Ângelo Montagner, ${ }^{2}$ Maria Inez Montagner |

${ }^{1}$ Cientista social, mestre e doutor em Saúde Coletiva. Professor da Universidade de Brasília - UnB. Endereço eletrônico: montagner@unb.br

${ }^{2}$ Cientista social, mestre e doutoranda em Saúde Coletiva, Departamento de Medicina Preventiva e Social, Unicamp.

Antes de comentar a obra em si, gostaríamos de ressaltar a trajetória da autora desse livro sobre as Ciências Sociais relacionadas à saúde no contexto brasileiro. Ana Maria Canesqui há muito vem acompanhando o desenvolvimento e crescimento desta área, testemunha que foi dos primórdios da sua institucionalização de fato ocorrida a partir da segunda metade da década de 1960, em conjunção com a expansão do ensino superior no Brasil e com a reforma universitária de 1968.

Publicou, neste sentido, alguns textos básicos para os pesquisadores da área sobre as ciências sociais em saúde $(1995 ; 1997$; 2000) sobre o próprio campo, além de outros temas, como nutrição e alimentação, antropologia em saúde e, mais recentemente, o livro Olhares socioantropológicos sobre os adoecidos crônicos (2007).

Assim, não é fato novo o olhar da autora sobre este campo, pois foi partícipe da consolidação do ensino e pesquisa das ciências sociais em saúde, ocorrida por meio da criação de revistas especializadas, do aperfeiçoamento dos congressos e organização das associações que apoiaram a institucionalização do setor, como a Abrasco e o Cebes.

A novidade deste trabalho é que ele reflete um amadurecimento, tanto desta área de atuação, quanto do pensamento da autora sobre as ciências sociais no campo da saúde. Como observadora atenta, ela atinge uma posição que a capacita a realizar um levantamento bastante completo e sistemático acerca do assunto, ao versar sobre o perfil dos intelectuais que escolheram a área da saúde (ou a ela se converteram); sobre o ensino dos profissionais de saúde e a pesquisa; sobre os pioneiros e posteriores cientistas sociais e pesquisadores que contribuíram para a consolidação e expansão desta área de conhecimento. 
O escopo de análise do livro alcança três décadas (1965-1995), período crucial no desenvolvimento das ciências sociais relacionadas à saúde. Apesar da concisão, nada fica a descoberto, pois os resultados apresentados representam o acúmulo de experiências e informações sobre a atuação dos cientistas sociais na área do pensamento em saúde.

Trata-se de uma obra sucinta, mas completa, dividida em três partes. A primeira mostra o perfil dos cientistas sociais que atuam no campo, como adentraram a área, sua formação, seus vínculos institucionais, região de atuação, o perfil de graduação e pós-graduação. A seguir, toma-se como objeto a compreensão da prática destes sujeitos, deslindando-se, nesta segunda parte, o métier do ensino de ciências sociais em saúde, objetivo e tarefa primeira destes profissionais; na terceira parte, o objeto é a produção acadêmica, os assuntos pesquisados e os conceitos e metodologias empregados, delineando-se a tensão entre as abordagens disciplinares das ciências sociais e temáticas tendentes à interdisciplinaridade.

$\mathrm{Na}$ introdução do livro, Canesqui faz uma pequena genealogia da institucionalização do campo, estabelecendo, de forma histórica, os marcos e as principais linhas de força da sua constituição. A autora expõe que de início as ciências sociais albergaram-se nas instituições médicas, especialmente nos departamentos de saúde pública, medicina social ou preventiva. Uma de suas vertentes, sob a rubrica "ciências da conduta", influenciou-se pelas ciências sociais norte-americanas que incentivaram a gradativa introdução das ciências sociais como forma de resolver seus dilemas oriundos de uma prática individualista e clínica, por meio dos movimentos da medicina preventiva e integral. Nos anos de 1970, outros projetos reformistas, como a medicina comunitária, tiveram seus efeitos, favorecendo positivamente os primórdios da introdução das ciências sociais na arena médica que sofreram o crivo crítico da corrente latino-americana de Medicina Social, que renovou este ensino e a pesquisa sob o marco histórico-estrutural.

A reforma universitária do governo autoritário de 1968 também propiciou a introdução das ciências sociais no ensino médico, reforçada posteriormente pelos novos cursos de pós-graduação em Medicina Social/Saúde Pública que arregimentaram profissionais das ciências humanas e sociais para o ambiente médico, com vistas a uma adequação aos novos currículos de graduação e pós-graduação. Como resultado, as ciências sociais introduziram-se nas escolas médicas e dialogam com todas as áreas de conhecimento aí presentes, sobretudo na chamada Saúde 
Coletiva. Essa especificidade conforma a práxis deste profissional, e sobre ela a autora discorre nos capítulos de seu livro.

A base para traçar o perfil dos profissionais foi o Catálogo Brasileiro de Cientistas Sociais em Saúde, criado pela Abrasco em 1995. Nele constaram todos os que atuavam na saúde e tinham formação na graduação ou pós-graduação em ciências sociais e humanas, em um total de 158. Esse catálogo foi o resultado de um esforço pioneiro da Comissão de Ciências Sociais em Saúde da Abrasco, então coordenada pela autora, de mapear quantitativa e qualitativamente os pesquisadores ligados ao campo. Tomou por base dados coletados em instituições da área, complementados durante eventos científicos diversos que haviam culminado com a realização do I Encontro Brasileiro de Ciências Sociais em Saúde em Belo Horizonte em 1993. A intenção foi identificar e agrupar os pesquisadores ligados às ciências sociais.

$\mathrm{Na}$ época, constatou-se um restrito número de profissionais, se compararmos com a situação norte-americana, que estavam ligados essencialmente ao setor público, concentrados na Região Sudeste, em especial no eixo Rio-São Paulo (71,0\%), formados majoritariamente nas ciências sociais e humanas $(73,0 \%)$. Os resultados apontam, segundo a autora, para uma maior incorporação de formados em ciências sociais, pois em 1970 apenas 17,6\% dos profissionais atuantes eram oriundos das ciências humanas.

Ao mesmo tempo, o perfil das atividades, do recrutamento e da incorporação destes profissionais mudou. No período inicial de 1964 a 1969, apenas 6\% dos profissionais inseriram-se na área como docente-pesquisador, enquanto na década de 1970, 26,5\% foram absorvidos durante a expansão do ensino, atuando como docentes-pesquisadores. Na década seguinte, apenas 19,0\% foram incorporados, demonstrando maior dificuldade de absorção destes profissionais. Na década de 1990, ganha força o pesquisador ligado a grupos de pesquisa e com vínculos formais tênues e provisórios. Além disso, com a política restritiva de reposição de quadros, a inserção de pesquisadores oriundos das ciências humanas tendia a diminuir, apesar da consolidação da área.

No capítulo 2, Canesqui discute como ocorreu a prática do ensino nas instituições da área, ressaltando o percurso histórico e as dificuldades recorrentes. Destaca que as primeiras experiências estiveram muito ligadas aos conteúdos de linha funcionalista de influência norte-americana, sendo substituídas 
posteriormente pelo pensamento hegemônico marxista-estruturalista nos anos 1970 e 1980, cuja abordagem macroestrutural privilegiou a análise da política e intervenção do Estado, os determinantes do processo saúde e doença e da prática médica em detrimento do plano microanalítico.

Como professora e formadora de recursos humanos de longa data na área, Canesqui comenta a dificuldade de ensinar o ponto de vista macroanalítico marxista e outros temas mais globalizantes, em um ambiente voltado para o pragmatismo e imediatez, próprio de uma formação focada na resolução de problemas práticos urgentes. Essas dificuldades aconteciam principalmente na formação médica mas se amenizavam nos cursos de especialização em saúde pública ou naqueles voltados para os serviços.

Segundo a autora, na residência médica em geral, a tendência mais recente é a de aproximação com as questôes mais prementes dos serviços e da rede assistencial, com conteúdos mais instrumentalizados e voltados para a resolução de problemas concretos, a despeito de uma certa crise na procura de residências na saúde coletiva/pública, fruto talvez de uma despolitização da sociedade brasileira. Na pós-graduação houve um afloramento de temáticas, baseadas em investimentos específicos dos diversos programas, ainda que mantivessem como central o referencial metodológico das ciências sociais.

Mesclando as informações do Catálogo da Abrasco com dados de trabalhos sobre o campo da saúde, a autora mapeia, em seguida, a produção acadêmica na área, no capítulo mais extenso sobre as antigas e novas tendências de institucionalização. Ela constata a tendência de especialização, em torno de objetos delimitados e específicos, ou por meio da demarcação de campos disciplinares já constituídos.

Neste terceiro capítulo, a autora identifica as disciplinas e assuntos de interesse dos cientistas sociais, através das suas respostas ao Catálogo da Abrasco, documentando a tensão entre os recortes temáticos e os disciplinares. Não se trata de revisão bibliográfica exaustiva sobre o assunto, como advertiu a autora, que recorreu a 200 citaçōes bibliográficas nacionais, selecionadas entre os autores mais expressivos nos temas pesquisados por cientistas sociais e profissionais de saúde que incorporaram os referenciais das ciências sociais.

Ao traçar um panorama das permanências e mudanças dos assuntos pesquisados, a autora destacou um conjunto de interesses que marcam a presença das ciências sociais na pesquisa em saúde. O leitor encontrará uma análise ampla 
e dinâmica dos temas pesquisados, tais como: sistemas terapêuticos ou alternativos de cura; políticas e instituições de saúde; saúde e doença; recursos humanos (formação, profissões, processo de trabalho); saúde reprodutiva, sexualidade e gênero; violência e saúde; educação e comunicação em saúde; planejamento, gestão e avaliação de serviços de saúde.

A análise oferece um quadro preciso das abordagens teórica, conceitual e metodológica dos assuntos, comparados nas décadas de 1970, 1980 e 1990, fornecendo ao leitor um panorama do estado da arte das ciências sociais em saúde no Brasil, suas diferentes vocações intelectuais, a produção acadêmica e as alterações ocorridas nas abordagens e suas tendências no fim da década de 1990, que encerrou o século XX.

A tensão entre a disciplinaridade e interdisciplinaridade foi uma característica apontada, ao lado da dificuldade em construir objetos híbridos no plano do conhecimento que rompam tanto as fronteiras disciplinares como a tendência à especialização temática ou disciplinar, além da maior diversidade e dispersão temática entre os profissionais pertencentes às instituições mais consolidadas em relação às menos consolidadas, onde existe maior dificuldade de formação de grupos de pesquisa.

Dentre os assuntos emergentes, o estudo aponta as preocupações com as distintas racionalidades terapêuticas como fenômenos não-residuais na sociedade contemporânea; os estudos sobre os limites e constrangimentos importantes à implementação do Sistema Único de Saúde, os processos participativos, descentralizadores e a municipalização, ao lado das reformas de setores específicos, como a atenção básica e a saúde mental. Os estudos antropológicos e as abordagens metodológicas qualitativas vêm contribuindo na compreensão e interpretação dos adoecimentos, nas suas dimensões físicas, sociais e culturais, das experiências e representações sociais da doença; das biotecnologias e seus impactos na vida. As pesquisas sobre o trabalho dos profissionais e equipes de saúde abordam os novos modelos assistenciais, enquanto o fenômeno da violência e saúde e suas diferentes dimensões (estrutural, cultural e de saúde) evidencia efeitos sobre a atenção médica e os indicadores de morbi-mortalidade, mobilizando os olhares sobre a complexidade e abordagens interdisciplinares entre as ciências sociais e a epidemiologia.

As preocupações com a informação em saúde acompanham o processo de reformulação da política de saúde, chamando a atenção dos comunicadores, educadores, jornalistas e outros profissionais, suscitando também o trabalho dos 
cientistas sociais, ao lado de renovadas aproximações da educação em saúde, tradicional campo da Saúde Pública. Aponta-se a tendência da contribuição das ciências sociais na avaliação dos profissionais e serviços, com potenciais estudos sobre a implementação, os efeitos das políticas de saúde e o uso das metodologias qualitativas.

Sem que o estudo tenha destacado como item específico o assunto "teorias e metodologias", cujo interesse manifesto nas respostas obtidas no Catálogo preencheu apenas 3,7\% das respostas, a autora aponta a relevância destas contribuiçôes ao campo da Saúde Coletiva, durante a década de 1990, destacando-se as reflexões sobre a combinação de métodos qualitativos e quantitativos, a sistematização das teorias e metodologia qualitativas, não reduzidas apenas às técnicas de coleta de informação mas permeando vários assuntos que usaram abordagens como a dialética-hermenêutica; as compreensivas, fenomenológicas e interpretativas desenvolvidas pelas ciências sociais, que reforçam sua necessária presença na área da Saúde Coletiva e da pesquisa em saúde.

Nas considerações finais, Ana Canesqui ressalta a diversidade metodológica e teórica das ciências sociais em saúde, sua atual heterodoxia e flexibilidade baseadas em teorias parciais e menos totalizantes, o que para autora é um indício de vitalidade. Ela aponta, por fim, a imperiosa necessidade de aproximação com outras disciplinas como a Epidemiologia, o Planejamento e a Gestão, permitindo aos cientistas sociais da área penetrarem nos meandros do poder que conformam a gestão das políticas de saúde no Brasil, as profissões e as relações com os usuários do sistema como um todo. Isto poderia fazer face às atuais dificuldades de institucionalização das Ciências Sociais no campo, a despeito da sua já comprovada importância para a Saúde Coletiva.

Breve, esta obra preenche a lacuna de uma obra introdutória e necessária de apresentação das ciências sociais na área da saúde, com todos os elementos essenciais elencados de forma didática embora aprofundada, de modo a dar conta de um período crucial da história do campo. Este painel dos profissionais que trabalham no ensino, do tipo de pesquisa e da produção científica mostra os investimentos e esforços daqueles chamados a atuar em uma interface nem sempre cômoda, mesmo se profícua e fundamental. 
Referências:

CANESQUI, Ana Maria (org.). Dilemas e desafios das Ciências Sociais na Saúde Coletiva. São Paulo: Hucitec, 1995.

_org.). Ciências Sociais e saúde. São Paulo: Hucitec, 1997.

__ (org.). Ciências Sociais e saúde para o ensino médico. São Paulo: Fapesp, 2000.

__ (org.). Olhares socioantropológicos sobre os adoecidos crônicos. São Paulo: Hucitec, 2007. 